\title{
Virtual Education Centre for the Development of Expert Skills and Competencies
}

\author{
http://dx.doi.org/ijac.v4i4.1747 \\ Tatjana Welzer ${ }^{1}$, Metka Zorič Venuti $^{1}$, Anthony E. Ward ${ }^{2}$, Marko Hölbl ${ }^{1}$, Marjan Družovec ${ }^{1}$ \\ ${ }^{1}$ University of Maribor, Maribor, Slovenia \\ ${ }^{2}$ University of York, Heslington, U.K
}

\begin{abstract}
The Virtual Education Centre for the development of expert skills and competencies provides intensive vocational courses (e-learning modules), for (primarily) employed learners who have the opportunity to develop their competencies in small pieces (steps) as part of an overall learning strategy. The well-known higher education institutions all over Europe are providers of e-learning modules, which ensure a multilingual approach and also demanding cultural awareness. The official name of the centre is Virtual Centre for Enterprise (VCE).
\end{abstract}

Index Terms-Virtual education centre, e-learning, skills, competences, cultural awareness, languages.

\section{INTRODUCTION}

Project Enhancing Lifelong Learning for the Electrical and Information Engineering Community is dedicated to establishing, first and foremost, a virtual education centre for the development of enterprise skills and competencies [1]. It is a Lifelong Learning Programme project, financed by the European Union and coordinated by the Universite Claude Bernard Lyon, France. Currently are in the project participating sixty partners from all around the Europe (30 countries). The centre provides vocational intensive courses primarily for employed learners with the workload of 1 ECTS. Through this opportunity, learners have the ability to develop their competences in small steps when they need, or wish, to do so [2].

Virtual Education Centre which is named Virtual Centre for Enterprise (VCE) is using as training fields Electrical and Information Engineering. The facilities of the centre are open to students at all levels of their education and to individuals of all ages [1]. The main activities enabled/supported by the VCE are the following:

- A reference repository of relevant research publications in the field of enterprise in Electrical and Information Engineering and in Pedagogy and Assessment;

- An e-learning system where individuals can register and select a module they would like to work on.

- Teaching resources (VCE e-modules) freely available for partners for their own teaching purposes;

- Learning resources for developing learners language skills in different foreign languages

- Get to know different cultures by using VCE on the base of participants from different countries.

Each VCE course is an e-module, developed in Moodle. It has clearly defined aims presented through professional content, communication, collaboration and differentiation [1]. Because of different languages and multicultural participation, as well as the use of an e-learning environment [2], learners can also be faced with obstacles in these points. We would especially like to point out the multilingualism and multiculturalism of the participants. Learners, teachers, mentors and course authors/developers have to be aware of the fact that project partners come from 30 countries and subsequently must take into account different languages and cultures. In this phase of development, most of the available courses are in English, but we plan to use also other languages.

In the paper, we want to point out the importance of different languages that are used, or will be used, in the VCE by different users (teachers, mentors, authors/developers and learners). At last but not least we have to point out also cross cultural communication (different languages, different cultures), which is actually cultural awareness, and which is often also a new skill for learners and other participants. The VCE possibilities are further corroborated in section IV.

\section{EXPERT COMPETENCES AND SKILLS}

People need a broad range of skills in order to contribute in the global world and take their place in the technological society of the twenty-first century. Studies have shown that the workplace is changing through technology, including the necessary skills and competencies, and that employees need to be able to change with them. While competencies are standardized as requirements for an individual to properly perform a specific job, skills are presented as a learned capacity to carry out pre-determined results -- often with the minimum of time, energy, or both. Competencies are also represented as the dynamic combination of knowledge, understanding, skills and abilities and are formed in various modules as well as assessed in different stages [12]. Competencies and skills can be general (time, management, teamwork, leadership, selfmotivation) or specific (selected languages and cultures, medicine, law, IT ...). We would like to concentrate on the specific competencies that are more domains and expertoriented. We plan to observe them as instrumental, interpersonal and systemic competencies. For instrumental, we mean cognitive abilities, methodological and technological abilities, as well as linguistic ability. Interpersonal competencies are more or less social skills with interaction and co-operation, while systemic competencies are abilities and skills concerning whole systems [12]. For our further work, language and culture skills and competencies are the most important. 
PAPER
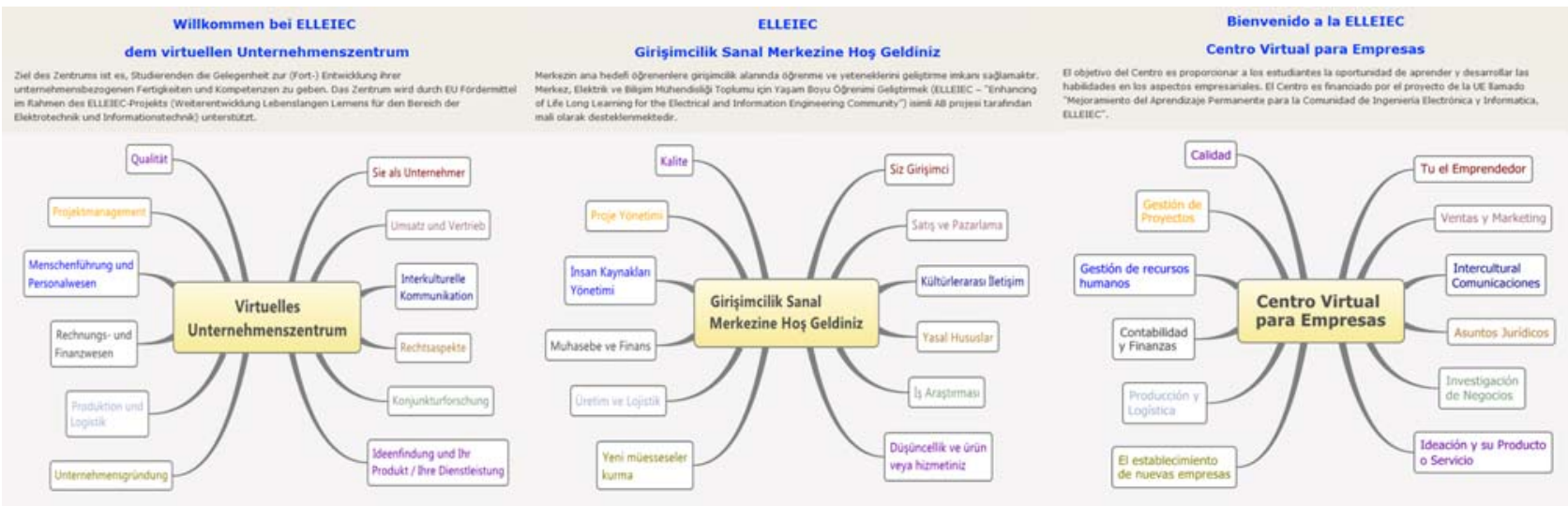

Figure 1. VCE welcome page in different languages

Culture is a word that has grown over centuries to reach its present, broad meaning [10]. In present-day discussions, culture has a complex history and diverse range of skills and competencies, which will later be defined and discussed in greater detail. We should also point out that culture also refers to different areas and domains from nation to sport and from office to community [10].

In addition to culture, language has also grown over the centuries as a combination of sounds that are recognised as words, which are culturally specific and have finally transformed into different languages that are spoken all around the world and encompass skills and competences as well. The historical development of languages has resulted in environmentally dependent languages, which greatly differentiate, even if they have the same name, such as English. For example, Shakespearean English [10] is very different from modern English -- to the point where contemporary skills and competencies are occasionally not enough to cope with the older version.

When studying human language, linguists focus on different aspects of the language systems like sound, structure and meaning on which we are mostly oriented in the VCE modules, although that collectively our knowledge of each aspect of the language system provides us with a holistic understanding of the nature of human language [13].

Independent of the expert domain in which we would like to show or improve skills and competencies, we are also faced with cultural and language skills and competencies. We have to point out the importance of both and try to build-in both in any domain. Their development can be supported by VCE modules, more detailed by the Cross Cultural Communication module.

\section{LANGUAGES AND CULTURAL AWARENESS}

In teaching and learning processes, language has an extremely important role. Misunderstandings can happen and cause serious mistakes if words are imprecise [9] or misunderstood. As previously mentioned, in the case of VCE, most participants will take part in the education process in what is most probably a foreign language. One exception will be the native English speakers, since most of the VCE modules are momentarily in English. Regardless of this, all students could be confounded by a language problem, since the tutor/teacher could speak a different language as the student. Before these misunderstandings can happen again, some ideas can get lost and the learner's skills and competencies can be lower than expected by the end of the education process. The result of the assessment is that both the teacher and learner are unsatisfied or even unhappy.

To avoid these obstacles, the learner needs more time for learning and understanding learning material and overcoming language barriers, as well as answering or preparing other materials in the module. For learners, this is a great opportunity to improve their language skills and expert vocabulary.

For language, we can also have another point of view. R.D.Lewis understands language as a poor communication tool unless each word or phrase is seen in its original cultural context [7]. This means that we also have to take care about culture and cultural awareness.

Today, we are confronted with many definitions of culture, available in literature, papers and on the Internet, written or presented by different authors. For example, Hofstede defines culture as a collective phenomenon, because it is shared with people who live or have lived within the same social environment. For him, a culture consists of unwritten rules in a social game. It is the collective programming of the mind that distinguishes the members of one group or category of people from another group or category of people [5], [6]. Also Liu, Volčič and Gallois define culture as a particular way of life of a group of people, comprising the deposit of knowledge, experience, beliefs, values, traditions, religion, notions of time, roles, spatial relations, worldviews, material objects and geographic territory [13]. A summary of definitions is well illustrated by cultural matrix depicted in Figure 2 [15].

According to our experience, when defining culture, it is even more important to clarify cultural awareness. Little or no cultural awareness means a poor understanding of intercultural dialogue, which can lead to blunders, and damaging consequences, especially in business, management and advertising [8], where cultural awareness seems to be of key importance for success. However, engineering and many other areas are also not immune to it [9]. For that reason, knowledge of cultural awareness should not be missed in any VCE module, while considering cultural awareness we can avoid cultural shock of participants. Namely by cultural shock the feelings of disorientation and anxiety can appear when familiar cultural norms are questioned in a new or at least different cultural environment [13]. 


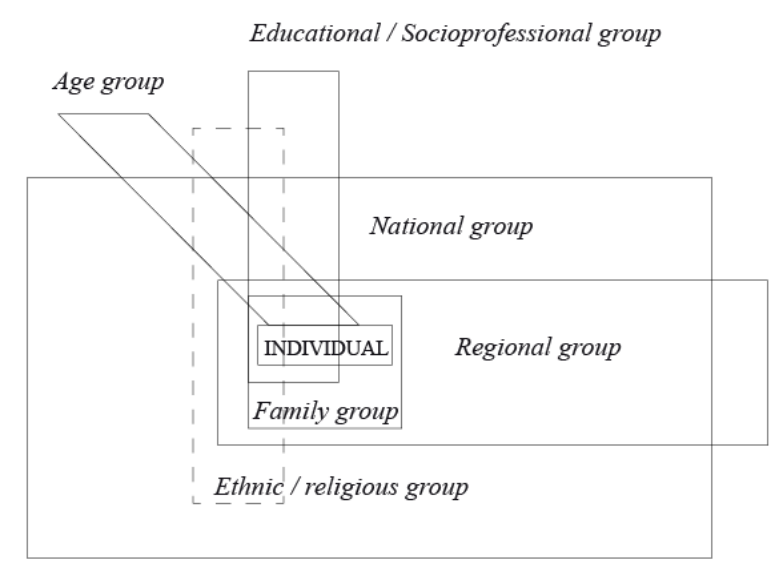

Figure 2. Cultural matrix

Cultural awareness is the foundation of communication, and it involves the ability to observe our cultural values, beliefs and perceptions from the outside [2]. It becomes important in communicating with people from other cultures, and we have to understand that people from different cultural environments, can understand, interpret and evaluate things in different ways [11]. Becoming aware of a culture is a difficult task since culture is not conscious of us - it is like water to fish - we live and breathe it [8]. To avoid these cultural obstacles and follow the mentioned definitions, teachers who are experts in cultural diversity have to introduce into VCE modules examples and discussions that cover different cultural points of view, offering different ways of communicating, collaborating and expressing support for cultural diversity. A small part of those skills is also given through the CCC module to improve the cultural competencies of learner.

\section{EXAmPle: CROSS CUltural COMMUNICATION MODULE}

Among the developed modules of VCE, there is also the Cross Cultural Communication module (CCC). Its role is twofold: it is one of the learning modules that learners can select, as well as a module that is designed in some way for all the participants. We expect that all of them have to be aware of the importance of different cultures, and that modules should give them some basic skills with regard to cross cultural communication. It is a special course that should, already in the beginning, help learners and other participants understand the importance of the topic and make them aware of the importance of culture in an information society and in global communication. By the rest of courses in our VCE, we expect the importance of culture to mostly be taken into account as a built-in knowledge in expert courses for electrical and information engineering. [11].

The Cross Cultural Communication course is developed in the educational e-environment Moodle. On Figure 3. you can see the visual presentation of the first page. Because of the project needs, the course is written in English, but for the future we expect that some of courses will be translated and developed in other European languages. In VCE, we have to expect that learners and teachers will come from different countries and that they will be aware that they are primarily communicating in different languages and are connected to different cultures. However, it can seem that many European cultures are nearly the

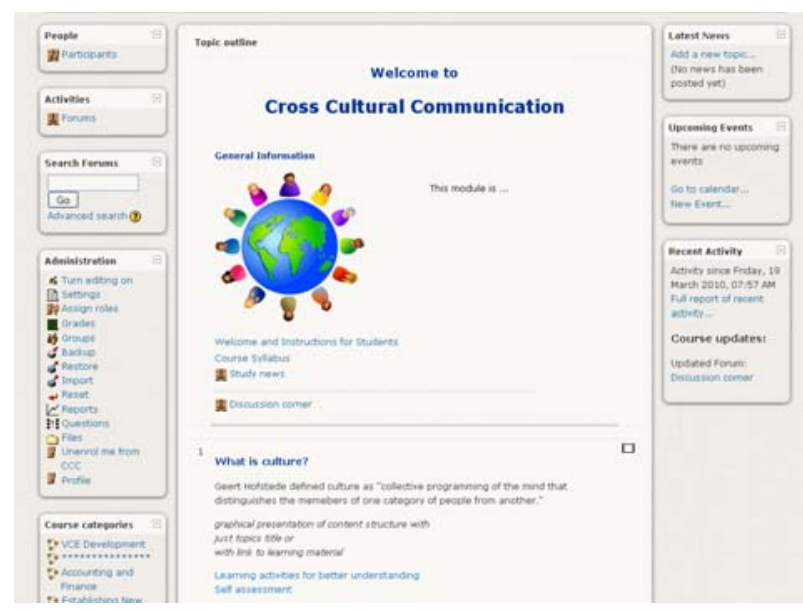

Figure 3. Cross Cultural communication Course Web Page [12]

same or at least similar. For that reason, the VCE welcome page is multilingual. On Figure 3., three available languages (English, Spanish, Turkish, French, Dutch, German, Slovenian and many others) are used [14].

In the VCE, we decided to build small learning blocks with the workload of 1ECTS. The reason for this decision is in the motivation of learners to take part in the VCE, while the centre gives them the opportunity to see quick results in self-learning, while at the same time gaining the confidence they need to cope with the workload in addition to their regular employment.

When considering the numbered facts, we are only able to present basic concepts in the CCC module, which should help foster the understanding of intercultural dialogue. Among these basic concepts are definitions about what culture is, and what cultural shock is, who is normal, what are cultural categories, what are linear-active and multi-active cultures, how to understand reactive cultures and inter-category comparisons.

For the advertising of the module, this is not enough. We have to prepare the specifications, which is a guide for the learner to base their final decision on selecting a module. In the specification, we present the title, short description, key words, level (introductory, intermediate, and advanced) also aims (goals), learning outcomes, learning sources, as well as the formative and summative assessment.

Assessments are very important, because on their basis, a final confirmation is given to the learner, which may be a crucial factor for the selection of a module. Regardless of how interesting, important and useful the module is, the assessment can be the point of decision for learner. In the CCC module, the assessment will be done via test, where the maximum amount of possible answers are available and the learner has to make just a decision for one or more according to instructions, and is only required to answer in their own words in a few cases.

\section{CONCLUSION}

In the present paper, we have tried to emphasise the importance of cultural and language skills and competencies in systems that are active in multicultural and multilingual environments and which can easily assume an international character, just as VEC does. In such multicultural and multilingual environments, we have to be aware of culture and the appearance of foreign languages in the 
PAPER

dialogue between different participants (learners, teachers, authors, tutors...).

If we are culturally aware, this means in general, that we are open to ideas about changing cultural attitudes or being sensitive to the difference between how we would like to be perceived by others and how we are actually perceived by others. Cultural awareness recognizes that we are shaped by our cultural background, which influences how we interpret the world around us, perceive ourselves and how we relate to other people [8], [11].

We have also recognised as a problem the understanding of different languages. We do not expect any significant problems with foreign languages between different participants in VCE, but misunderstandings can happen very easily, and with inconvenient consequences [9].This awareness is also one of reasons that are VCE modules prepared in English and not in national languages. But also by English modules we have to be aware of misunderstandings, while for most of projects participants English is the main communication language, while only some are English native speakers. Nevertheless also native speakers need a kind of dictionary to understand or to limit some of meanings, especially in expert topics and domains.

\section{REFERENCES}

[1] C. Perra, H. Yahoui, T. Ward, "An Entrepreneurship Center in the lifelong learning spirit", ITHET 2010, IEEE, 2010, pp. 215-218.

[2] T. Welzer, M. Bonačić, M. Zorič Venuti, "Cultural awareness in information society", $20^{\text {th }}$ EAEEIA annual conference Innovation in education for electrical and information engineering, 2009, IEEE, 4 f, 2009.

[3] H. Yahoui, "ELLEIEC - Enhancing Lifelong Learning for the Electrical and Information Engineering Community", Project Report, 2010.

[4] S.C. Schneider, J-L. Barsoux, "Managing Across Cultures", Prentice Hall, Harlow, 2003.

[5] G. Hofstede, "Culture's Consequences, Comparing Values, Behaviors, Institutions and Organizations Across Nations", Sage Publications, Thousand Oaks, 2001.
[6] G. Hofstede, G.J. Hofstede, "Cultures and Organizations: Software of the Mind: Intercultural Cooperation and its Importance for Survival", McGraw-Hill, New York, 2004.

[7] R.D. Lewis, "When Cultures Collide, Managing Successfully Across Cultures", Nicholas Brealey Publishing, London, 2007.

[8] B. Farsides, "Cultural Awareness and Common Understanding: The Key to Informed Consent?" http://tbethic.org/conf18.htm, last visit September $25^{\text {th }} 2010$.

[9] M. Zorič Venuti, T. Welzer, A.E.Ward, "Key Issues Concerning the Simultaneous Development of Technical and Linguistic Components in a single E-Module", DeSE 2010, IEEE, 2010.

[10] E. Baldwin et al., "Introducing Cultural Studies", Prentice Hall, Harlow, 2004.

[11] Welzer, T., Družovec M., Cafnik P., Zorič Venuti M., Jaakkola H. 2010. "Awareness of Culture in e-learning". ITHET 2010, IEEE, pp. 312-315.

[12] J. Gonzales, R. Wagenaar, "Universities' contribution to the Bologna Process, An introduction", $2^{\text {nd }}$ Edition, Publicaciones de la Universidad de Deusto, 2008.

[13] S. Liu, Z. Volčič, C. Gallois, "Introducing Intercultural Communication: Global Cultures and Contexts", Sage, London, 2011.

\section{AUTHORS}

Tatjana Welzer, Marko Hölbl and Marjan Družovec are with the University of Maribor, Faculty of Electrical Engineering and Computer Science, Maribor, Slovenia (email: welzer@uni-mb.si, marko.holbl@uni-mb.si, marjan.druzovec@uni-mb.si)

Metka Zorič Venuti is with the University of Maribor, Center of E-learning and Lifelong Learning, Maribor, Slovenia (e-mail: zoric-venuti@uni-mb.si)

Anthony. E. Ward is with the University of York, Centre for Excellence in Teaching and Learning in Enterprise, Heslington, UK (e-mail: aew6@york.ac.uk)

This work was supported by the EU Lifelong Learning Programme Project Number: 142814-LLP-1-2008-FR-ERASMUS-ENW. This article is an extended version of a paper presented at the International Conference EDUCON2011, held in April 2011 at PSUT, in Amman, Jordan. Received 12 July 2011. Published as resubmitted by the authors 15 October 2011 . 